\title{
Corrigendum: Inhibitory Network Bistability Explains Increased Interneuronal Activity Prior to Seizure Onset
}

\author{
Scott Rich ${ }^{1 *}$, Homeira Moradi Chameh ${ }^{1}$, Marjan Rafiee ${ }^{1}$, Katie Ferguson ${ }^{1 \neq}$, \\ Frances K. Skinner ${ }^{1,2 \dagger}$ and Taufik A. Valiante ${ }^{1,3,4,5,6+}$ \\ ${ }^{1}$ Division of Clinical and Computational Neuroscience, Krembil Research Institute, University Health Network, Toronto, ON, \\ Canada, ${ }^{2}$ Departments of Medicine (Neurology) and Physiology, University of Toronto, Toronto, ON, Canada, ${ }^{3}$ Institute of \\ Biomaterials and Biomedical Engineering, University of Toronto, Toronto, ON, Canada, ${ }^{4}$ Institute of Medical Science, \\ University of Toronto, Toronto, ON, Canada, ${ }^{5}$ Division of Neurosurgery, Department of Surgery, University of Toronto, \\ Toronto, ON, Canada, ${ }^{6}$ Department of Electrical and Computer Engineering, University of Toronto, Toronto, ON, Canada
}

Keywords: epilepsy, seizure, bistability, computational neuroscience, synchrony, inhibitory network, interneurons

OPEN ACCESS

Edited by:

Qian-Quan Sun

University of Wyoming, United States

Reviewed by:

Qing Yun Wang,

Beihang University, China

*Correspondence:

Scott Rich

sbrich@umich.edu

${ }^{\dagger}$ These authors share senior authorship

¥Present address: Katie Ferguson,

Department of Neuroscience, Yale University School of Medicine, New Haven, CT, United States

Received: 18 June 2021 Accepted: 12 August 2021 Published: 06 September 2021

Citation: Rich S, Moradi Chameh H, Rafiee M,

Ferguson K, Skinner FK and

Valiante TA (2021) Corrigendum: Inhibitory Network Bistability Explains Increased Interneuronal Activity Prior

to Seizure Onset.

Front. Neural Circuits 15:727442.

doi: 10.3389/fncir.2021.727442

\section{A Corrigendum on}

Inhibitory Network Bistability Explains Increased Interneuronal Activity Prior to Seizure Onset

by Rich, S., Chameh, H. M., Rafiee, M., Ferguson, K., Skinner, F. K., and Valiante, T. A. (2020). Front. Neural Circuits 13:81. doi: 10.3389/fncir.2019.00081

In the original article, there was a mistake in Table 1 as published. The values of $d$ and $k_{\text {low }}$ were swapped between the Control and 4-AP settings in this table, but correct in the associated code. The corrected Table 1 appears below.

The authors apologize for this error and state that this does not change the scientific conclusions of the article in any way. The original article has been updated.

\section{REFERENCES}

Ferguson, K. A., Huh, C. Y., Amilhon, B., Williams, S., and Skinner, F. K. (2013). Experimentally constrained ca1 fast-firing parvalbumin-positive interneuron network models exhibit sharp transitions into coherent high frequency rhythms. Front. Comput. Neurosci. 7:144. doi: 10.3389/fncom.2013.00144

Williams, S. B., and Hablitz, J. J. (2015). Differential modulation of repetitive firing and synchronous network activity in neocortical interneurons by inhibition of A-type $\mathrm{K}+$ channels and Ih. Front. Cell. Neurosci. 9:89. doi: $10.3389 /$ fncel.2015.00089

Publisher's Note: All claims expressed in this article are solely those of the authors and do not necessarily represent those of their affiliated organizations, or those of the publisher, the editors and the reviewers. Any product that may be evaluated in this article, or claim that may be made by its manufacturer, is not guaranteed or endorsed by the publisher.

Copyright (c) 2021 Rich, Moradi Chameh, Rafiee, Ferguson, Skinner and Valiante. This is an open-access article distributed under the terms of the Creative Commons Attribution License (CC BY). The use, distribution or reproduction in other forums is permitted, provided the original author(s) and the copyright owner(s) are credited and that the original publication in this journal is cited, in accordance with accepted academic practice. No use, distribution or reproduction is permitted which does not comply with these terms. 
TABLE 1 | Parameters used in neuron models.

\begin{tabular}{lccl}
\hline Parameter & $\begin{array}{c}\text { Value } \\
\text { (Control) }\end{array}$ & $\begin{array}{c}\text { Value } \\
\text { (4-AP) }\end{array}$ & Rationale \\
\hline$C_{m}$ & $73 \mathrm{pF}$ & $49 \mathrm{pF}$ & Unpublished in-house experiment \\
$v_{r}$ & $-60.6 \mathrm{mV}$ & $-60.6 \mathrm{mV}$ & Ferguson et al. (2013) \\
$v_{t}$ & $-43.1 \mathrm{mV}$ & $-43.1 \mathrm{mV}$ & Ferguson et al. (2013) \\
$v_{\text {peak }}$ & $2.5 \mathrm{mV}$ & $2.5 \mathrm{mV}$ & Ferguson et al. (2013) \\
$a$ & $0.01 \mathrm{~ms}^{-1}$ & $0.01 \mathrm{~ms}^{-1}$ & Parameter influences rheobase and adaptation exhibited by model \\
$b$ & $-0.2 \mathrm{nS}$ & $-0.4 \mathrm{nS}$ & Parameter influences rheobase and adaptation exhibited by model \\
$c$ & $-67 \mathrm{mV}$ & $-67 \mathrm{mV}$ & Ferguson et al. (2013) \\
$d$ & $0.75 \mathrm{pA}$ & $1.25 \mathrm{pA}$ & Parameter influences rheobase and adaptation exhibited by model \\
$k_{\text {low }}$ & $0.6 \mathrm{nS} / \mathrm{mV}$ & $0.4 \mathrm{nS} / \mathrm{mV}$ & Parameter influences rheobase and adaptation exhibited by model \\
$k_{\text {high }}$ & $2 \mathrm{nS} / \mathrm{mV}$ & $2 \mathrm{nS} / \mathrm{mV}$ & Parameter influences rheobase and adaptation exhibited by model
\end{tabular}

*Differences in rheobase and adaptation in control and 4-AP neurons are features shown by Williams and Hablitz (2015) as well as observed in our un-published in-house experiment. 